\title{
Metabolic effects of bariatric surgery on type 2 diabetes mellitus
}

\author{
M. Mahir Özmen \\ Department of General Surgery, Hacettepe University Faculty of Medicine, Ankara, Turkey
}

\begin{abstract}
Type 2 diabetes mellitus (T2D) develops in adulthood, and its exact etiology is still unknown. Obesity is major independent risk factor for T2D, as it is closely associated with insulin resistance. Bariatric surgery was initially used to induce weight loss in obese patients. However, it was observed that it also results in improvement in many comorbidities, including T2D. Curing diabetes cannot yet be considered a goal of bariatric surgery, but it is a serendipitous benefit. Mechanism of the effects of bariatric surgery on T2D was discussed in this review.
\end{abstract}

Keywords: Metabolic effects; obesity; surgery; type 2 diabetes.

\section{Introduction}

Obesity is a result of deranged energy homeostasis which is often the consequence of dysfunction in multiple neuro-enteric systems. ${ }^{[1]}$ According to WHO, $>1.6$ billion adults are overweight and $>400$ million are obese, and it is estimated that the numbers will have increased to $>2.3$ billion overweight and $>500$ million obese by $2015 .^{[2]}$

Type 2 diabetes mellitus (T2D) develops in adulthood, and its exact etiology is still unknown. T2D rates are also increasing alongside obesity with currently over 312 million people affected by diabetes worldwide. Therefore, it is known as twin pandemics. T2D is associated with markedly increased risk of heart disease and stroke, micro-and macrovascular consequences, retinopathy, and kidney failure. ${ }^{[3]}$ Long-term anti-diabetic diet compliance is poor even when supported by pharmacotherapy, and 50-90\% of the patients are unable to achieve adequate control.
Only 50\% of diabetic patients are able to achieve glycated hemoglobin (HbA1c) < $7 \%$ with medical therapy as recommended by the American Diabetic Association..$^{[1]}$

\section{Mechanism of 'Diabesity'}

Obesity is also found to be a major independent risk factor for T2D as it is closely associated with insulin resistance, which, in connection, is associated with loss of function of $\beta$-cells resulting in T2D. ${ }^{[4]}$ Obesity will eventually lead to glucose intolerance due to stress failure of the beta cells in predisposed individuals. ${ }^{[4]}$ Studies have revealed that 60 genes are associated with the increased risk of T2D. ${ }^{[5]}$ The term diabesity defines the effects of excess fat on many organs involved in glucose homeostasis. Adipose dysfunction will eventually result in cardiovascular disease and mortality due to metabolic disease state caused by 
pathogenic mediators and lipotoxicity. ${ }^{[6,7]} \mathrm{T} 2 \mathrm{D}$ is a lifetime disease, and currently no medical cure exists. Bariatric surgery was initially used to induce weight loss in morbidly obese patients. However, it turned out that it also results in improving many obesity related comorbidities including T2D. ${ }^{[8]}$

Therefore, the metabolic effects of bariatric surgery cannot be explained by weight loss only as reduction of metabolically active adipose tissue will improve the metabolic diseases. ${ }^{[9-11]}$ Today, although curing diabetes cannot yet be considered a goal of bariatric surgery, it may be considered a serendipitous benefit.

\section{Mechanism of Effects of Bariatric Surgery}

The glycemic outcome of bariatric surgery was defined long before and summarized in Table 1 below. ${ }^{[12-14]}$ Remission is defined as achieving glycaemia below the diabetic range in the absence of active pharmacologic (anti-hyperglycemic medications, immunosuppressive medications) or surgical (ongoing procedures like repeated replacements of endo-luminal devices) therapy. Remission can be characterized as partial or complete. ${ }^{[13]}$

Since the description ofremission after Roux-en-Y gastric bypass (RYGB) in morbidly obese patients with diabetes by Pories et al., other groups have verified the benefits of commonly performed laparoscopic bariatric procedures on T2D. ${ }^{[12,15-19]}$ The emergence of a large body of literature supporting surgical treatment of diabetes has led the International Diabetes Federation (IDF) and American Diabetes Association (ADA) to recognize bariatric surgery as an effective treatment option for obese patients with T2D. ${ }^{[20,21]}$

Bariatric surgery is a form of gastrointestinal surgery that aims at reducing the amount of food intake and/or the absorption of nutrients at the intestinal level. Bariatric surgery procedures fall into the following categories:

(i) Restrictive procedures: the aim is to limit the amount of food intake by reducing the size of the stomach.

(ii) Malabsorptive procedures: the aim is to limit the absorption of food in the intestinal tract by bypassing a portion of the small intestine to varying degrees.

(iii) Combination of both restriction and malabsorption.

The most commonly used standard bariatric surgery procedures are (1) Adjustable gastric banding (AGB), which is solely restrictive; (2) Roux-en-Y gastric bypass (RYGB), which has both restrictive and malabsorptive components; (3) Single anastomosis gastric bypass (SAGB), which is also mainly malabsorptive; (4) Sleeve gastrectomy, which is another solely restrictive procedure; and (5) Biliopancreatic diversion with duodenal switch (BPDDS), which is amore radical restrictive and malabsorptive procedure. ${ }^{[11]}$ Metabolic effects of bariatric surgery might be classified as:

a. Weight loss (WL) effect,

b. Weight loss (WL) independent effects (improvements in glycaemia, insulin resistance and $\beta$-cell dysfunction)

c. Other metabolic effects (on lipid profile, blood pressure and inflammation)

Table 1. Definitions for the glycemic outcome of bariatric surgery. Table was copied from Brethauer SA, et al. and based on consensus definitions ${ }^{[12-14]}$

\begin{tabular}{|c|c|}
\hline Outcome & Definition \\
\hline Complete remission & $\begin{array}{l}\text { Normal measures of glucose metabolism }(\mathrm{A} 1 \mathrm{C}<6 \% \text {, FBG }<100 \mathrm{mg} / \mathrm{dL}) \text { for } 1 \mathrm{yr} \text { in the } \\
\text { absence of anti-diabetic medications. }\end{array}$ \\
\hline Partial remission & $\begin{array}{l}\text { Sub-diabetic hyperglycemia (A1C 6\%-6.4\%, FBG } 100-125 \mathrm{mg} / \mathrm{dL} \text { ) for } 1 \mathrm{yr} \text { in the } \\
\text { absence of anti-diabetic medications. }\end{array}$ \\
\hline Improvement & $\begin{array}{l}\text { Significant reduction in } \mathrm{A} 1 \mathrm{C} \text { (by }>1 \% \text { ) or } \mathrm{FBG} \text { (by }>25 \mathrm{mg} / \mathrm{dL} \text { ) OR reduction in } \mathrm{A} 1 \mathrm{C} \\
\text { and } \mathrm{FBG} \text { accompanied by a decrease in anti-diabetic medication requirement (by } \\
\text { discontinuing insulin or } 1 \text { oral agent, or } 1 / 2 \text { reduction in dose) for at least } 1 \mathrm{yr} \\
\text { duration. }\end{array}$ \\
\hline Unchanged & The absence of remission or improvement as described earlier. \\
\hline Recurrence & $\begin{array}{l}\text { FBG or } \mathrm{A} 1 \mathrm{C} \text { in the diabetic range ( } \geq 126 \mathrm{mg} / \mathrm{dL} \text { and } \geq 6.5 \% \text {, respectively) } \mathrm{OR} \text { need for } \\
\text { antidiabetic medication after initial complete or partial remission. }\end{array}$ \\
\hline
\end{tabular}


According to IDF statements, efficacy of the treatment should be evaluated by checking glycated hemoglobin level, C-peptide, fasting glycaemia, insulin levels, lipid profile, monitoring arterial blood pressure, and weight loss. ${ }^{[20]}$

Metabolic effects of restrictive procedures are usually based on WL and caloric restriction (except sleeve gastrectomy in which ghrelin secretion is also decreased); whereas, any procedure including gastrointestinal bypass exhibits significant hormonal changes after surgery where the glycemic control is acute and immediate via an anti-diabetic weight-independent mechanism even before weight loss after surgery. ${ }^{[22]}$ Interestingly, restrictive techniques result in lower rates of diabetes remission than mixed procedures, suggesting that gastrointestinal tract changes after malabsorptive procedures are involved in diabetes control (48\% for gastric banding vs $84 \%$ for RYGB and $98 \%$ for BPD. ${ }^{[23,24]}$ Therefore, diabetes resolution is not a result of weight loss alone.

The main suggested hypotheses of thepossible related mechanisms are listed below: ${ }^{[2]}$

- Caloric restriction hypothesis

- Ghrelin hypothesis

- Upper intestinal (foregut) hypothesis

- Lower intestinal (hindgut) hypothesis

- Gut microbiota hypothesis

- Branched chain amino acids hypothesis

\section{Caloric Restriction Hypothesis}

According to this hypothesis, the remission of T2D after metabolic surgery is due to postoperative caloric restriction resulting in improved hepatic insulin sensitivity with reduced hepatic gluconeogenesis; however, there is no effect on muscle insulin sensitivity unless greater weight loss is achieved in obese subjects. The most prominent glycemic effects are the decrease in insulin resistance and the increase in early phase insulin release. Nevertheless, the interaction of multiple organ-related pathways involving the brain, gut, liver, pancreas, muscle, adipose tissues, and other undiscovered tissues may result in dramatic resolution of the diabetic state..$^{[11,26,27]}$ It was shown that patients with RYGB had higher rates of diabetes remission than LAGB ( $72 \%$ vs $17 \%$ ) in 2 years despite similar weight losses of $30 \% .{ }^{[28]}$ This hypothesis fails to explain why the remission of T2D is better and faster after bypass than AGB. It also does not explain the superiority of glycemic control achieved after RYGB vs equivalent weight loss from dieting. ${ }^{[29]}$

\section{Ghrelin Hypothesis}

Ghrelin is a circulating orexigenic gut hormone produced predominantly $(90 \%)$ by the fundus of the stomach, which has stimulatory effects on growth hormone release and also stimulates appetite and food intake. ${ }^{[30]}$ It is also produced in small amounts from the pancreas, intestine, placenta, kidney, pituitary gland, and hypothalamus. Thus, ghrelin levels increase before meals to signal hunger to the brain, specifically to the areas of the hypothalamic feeding centers. The regulation of ghrelin may be altered by bariatric surgery. It is undoubtedly decreased after sleeve gastrectomy. ${ }^{[31]}$ However, ghrelin levels are inconsistent, and the levels can increase, decrease or do not change after gastric bypass surgery. ${ }^{[1,32]}$

In addition to its effects on feeding behavior, ghrelin has a role in the regulation of glucose homeostasis; however, mechanisms by which ghrelin suppresses insulin secretion are not well understood yet. ${ }^{[33]}$

\section{Upper Intestinal Hypothesis}

It is called as the foregut hypothesis and based on an animal study by Rubino. ${ }^{[34]}$ In his study, it was shown that the exclusion of a short segment of proximal small intestine (primarily the duodenum) produces direct anti-diabetes effects, probably via one or more unidentified duodenal factors that influence glucose homoeostasis. This suggestion is supported by the results of the duodenal-jejunal bypass (DJB) procedure which maintains the gastric volume intact while bypassing the entire duodenum and the proximal jejunum. ${ }^{[35]}$

Additional support for this hypothesis comes from the endoluminal duodenal sleeve procedure which markedly improves glucose tolerance independently of weight loss in animals and humans. ${ }^{[36,37]}$ It has also been shown very recently that a duodenal bypass procedure without gastric restriction does not resolve $\mathrm{T} 2 \mathrm{D}$, in conflict with the foregut hypothesis. ${ }^{[38]}$

\section{Lower Intestinal Hypothesis}

It is also called the hindgut hypothesis based on the rapid delivery of nutrients to the distal bowel, thus producing 
a physiologic signal that improves glucose homeostasis. The potential mediators are glucagon-like peptide-1 (GLP-1), GIP (incretin effect) and peptide YY (non-incretin). ${ }^{[39]}$ This hypothesis is proposed to explain the rapid T2Dremission after RYGB and BPD. It has attracted huge interest because it involves active glucagon-like peptide-1 (GLP-1) which potentiates insulin secretion. ${ }^{[40]}$ Increased GLP-1 and P-YY levels after bypass surgery result in decreased appetite and increase in satiety, which is supported by an inhibition of this hormones by using octreotide after RYGB resulting in increased appetite. ${ }^{[4]]}$ Loss of appetite and increase in satiety result in long term success of WL if supported by a diet including lower glycemic index food.

\section{Gut Microbiota Hypothesis}

Gut microbiota refers to billions of microorganisms inhabiting the mammalian gastrointestinal tract. Microbiota of the intestine can affect the control of energy metabolism by increasing the energy harvested from the diet; thus, changes in the gut microbiota might contribute to the epidemics of obesity and T2D in humans. ${ }^{[42]}$ The mechanisms through which the microbiota exerts its beneficial or detrimental influences remain largely undefined.

\section{Branched-Chain Amino-Acids (BCAAs) Hypothesis and Bile Acids}

The concentrations of branched-chain amino acids (leucine, isoleucine, and valine) have been long known to be increased in obese individuals, and the increase has been directly correlated with the fasting insulin concentration, a marker of insulin resistance. ${ }^{[43]}$

The re-route of nutrients due to altered physio-anatomy after gastric bypass may also affect the entero-hepatic recirculation of bile acids and contribute to improved glycemic control. ${ }^{[44]}$ It has also been shown that $24 \mathrm{~h}$ basal energy expenditure is increased in patients with RYGB as compared to patients with vertical bad gastroplasty, who have lost the same amount of weight. ${ }^{[45]}$ It was thought that this was due to the presence of bile in the ileum. ${ }^{[44]}$ Therefore, it seems that the manipulation of bile acid homeostasis might be an attractive approach for T2D.

\section{Review of the Studies}

As Allen RE et al. have pointed out there might be another possible mechanism that should be added to the current list of potential explanations for immediate glycemic control after surgery: enhanced production in the lower intestine of a substance which opens an alternative insulin-independent pathway for glucose transport. ${ }^{[25]}$

Carlsson LMS, et al. have found in Swedish obese subjects study that bariatric surgery promotes remission of established T2D in 48-95\%. ${ }^{[46]}$ It has also been shown that diabetes related death risk is reduced by $92 \%$, and during the 15 years of follow up, risk of development of new T2D is also decreased by $87 \% .{ }^{[46]}$ Subgroup analyses by Sjöström $\mathrm{L}$ et al. have revealed that after surgery, remission rate of diabetes is better than controls in 2 years ( $72 \%$ vs. $21 \%$ ) and in 10 years (36\% vs. $13 \%$ ). ${ }^{[47]}$ They have also found that the rate of new onset diabetes is better in surgery group than in normal populations both in 2 and 10 years ( $1 \%$ vs. $8 \%$ and $8 \%$ vs. $24 \%$, respectively). They have also evaluated the effect of the duration of diabetes on remission results and found that the shorter the duration of diabetes, the better the results.

In their meta-analyses covering the studies between 2003-2012, Chang SH, et al. included 161.756 patients in 161 studies (37RCTs and 127 observational studies) and found better remission rates after gastric bypass surgery as compared to gastric band, sleeve gastrectomy, and controls ( $95 \%$ vs. $73 \%$ vs. $85 \%$ vs. $18 \%$, respectively). ${ }^{[48]}$

Schauer PR, et al. have compared the effects of bariatric surgery vs intensive medical therapy (MT) in obese patients with diabetes in a RCT and published the $1^{\text {st }}$ and $3^{\text {rd }}$ year follow up results. ${ }^{[4,50]}$ They have included 50 patients in each group of GB, SG and MT. They have assessed the glycemic control by fasting glucose and glycated hemoglobin (HbA1c) levels. Results are shown in Table 2. Low remission rates in these studies might be due to the inclusion criteria of the patients (longer duration of diabetes ( $>8$ years), higher use of insulin injections among patients (58\%), and patients with more severe diseases $($ HbA1c $=8.9-9.5)$. However, it seems that surgery is still the better means of control of diabetes as compared to medical therapy.

Table 2. Comparison of the effects of gastric bypass (GB), sleeve gastrectomy (SG) and medical therapy (MT) on T2D in the $1^{\text {st }}$ and $3^{\text {rd }}$ year after surgery ${ }^{[4,50]}$

GB (50) SG (50) MT (50)

$\begin{array}{lllc}\text { PO } 1^{\text {st }} \text { year } & 42 \% & 37 \% & 12 \% \\ \text { PO } 3^{\text {rd }} \text { year } & 38 \% & 24 \% & 5 \%\end{array}$




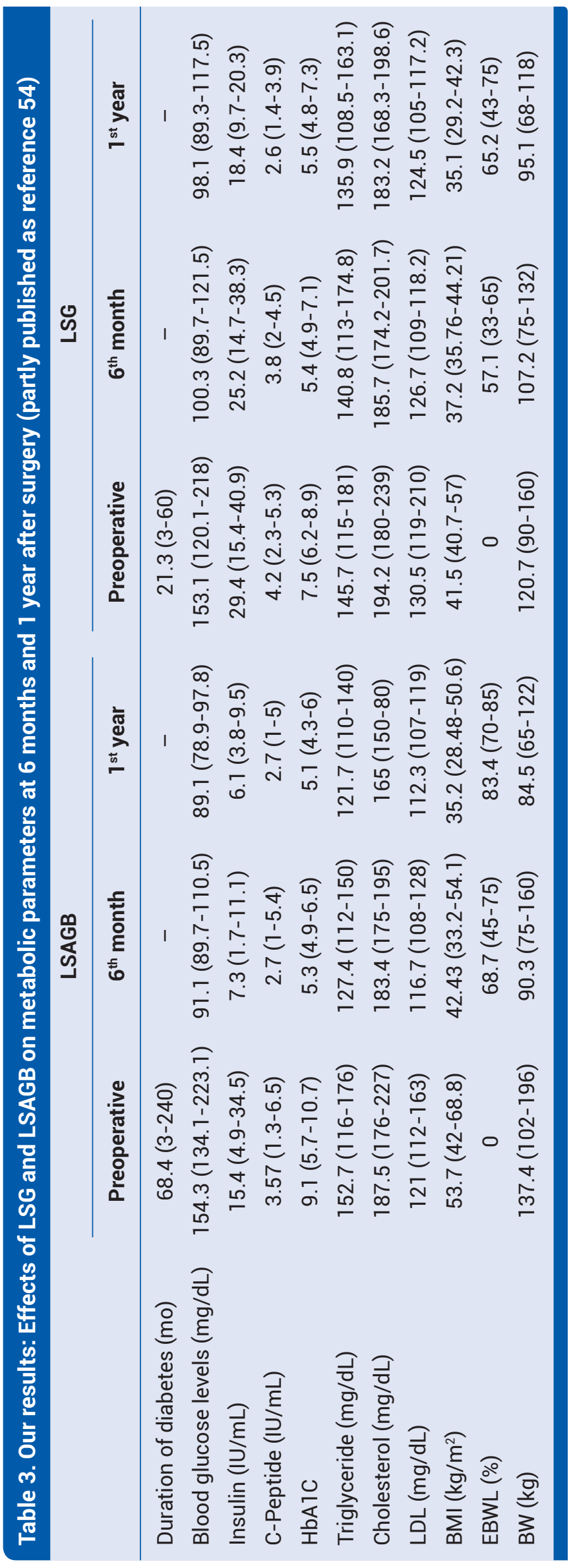

In another meta-analyses by Ribaric G, et al., 16 studies (5RCTs) with 3076 patients with bariatric surgery and 3055 patients with conventional or no weight loss therapy were analyzed. The overall T2D remission rate for surgery vs conventional group was $63.5 \%$ vs. $15.6 \%$ with the mean follow-up of 17.3 months. They concluded that bariatric surgery was more effective than conventional therapy in achieving weight loss, HbA1c and blood glucose reduction and diabetes remission. ${ }^{[51]}$

In his study, Lee WJ compared the effects of single anastomosis gastric bypass (SAGB) tosleeve gastrectomy on diabetes. ${ }^{[52]}$ Although the sample size was too small, they were able to reach the significance level and found that SAGB was better in controlling diabetes in 5 years with better incretin effects. In another multi institutional study, they found that patients with a diabetes duration of $<5$ years had a better diabetes remission rate than patients with duration of diabetes $>5$ years ( $90.3 \%$ vs. $57.1 \%)$, and patients with BMI $>30 \mathrm{~kg} / \mathrm{m}^{2}$ had a better diabetes remission rate than those with $\mathrm{BMI}<30 \mathrm{~kg} / \mathrm{m}^{2}(78.7 \%$ vs. $62.5 \%)$. ${ }^{[3]}$

\section{Our Results ${ }^{[54]}$}

244 morbidly obese patients operated on at Hacettepe University by the same surgical team between June 2013 and December 2014 were included into the study. 17 patients had revision surgery. Rest of the patients were primary cases on whom either laparoscopic sleeve gastrectomy (LSG, $\mathrm{n}=111$ ) or laparoscopic single anastomosis gastric bypass (LSAGB, $n=116$ ) were performed. These groups were evaluated in terms of metabolic parameters and resolution of the concomitant disease.

Among the LSAGB group, 83 patients were diabetic (10M) and 33 patients were non-diabetic. Mean body weight of the diabetic patients was 137.4 (102-196) kg. Mean duration of follow up was 10.2 (1-18) months. At the end of the follow up period, mean body weight dropped to 84.5 (65-122) kg. Mean HBA1c dropped from 9.1\% (5.7-10.7) to 5.1\% (4.3-6). Furthermore, preoperative serum insulin and C-peptide which were $15.4 \mathrm{IU} / \mathrm{mL}$ (4.9-34.5) and 3.57 $\mathrm{IU} / \mathrm{mL}(1.3-6.5)$ dropped to $6.1 \mathrm{IU} / \mathrm{mL}(3.8-9.5)$ and $2.7 \mathrm{IU} /$ $\mathrm{mL}(1-5)$.

Among the LSG group, 25 were diabetic (12M) and 86 were non-diabetic $(6 \mathrm{M})$. Mean body weight of the diabetic patients was 120.7 (90-160) kg. Mean duration of follow up was 10.3 (1-18) months. At the end of the follow up period, mean body weight dropped to $95.1(68-118) \mathrm{kg}$. Mean HBA1c dropped from $7.5 \%(6.2-8.9)$ to $5.5 \%(4.8-7.3)$. 


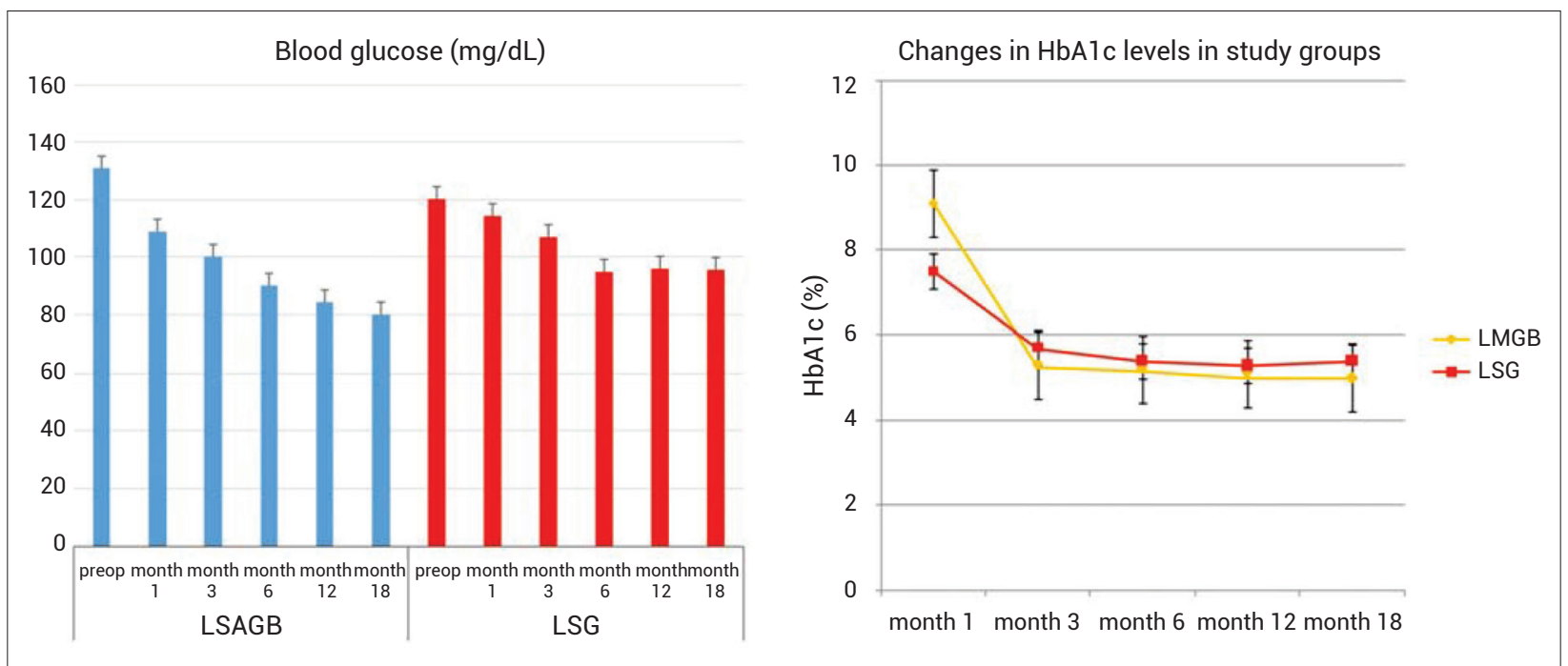

Figure 1. Changes in fasting blood glucose and HbA1c levels [LMGB > LSG (month 3) p<0.05].

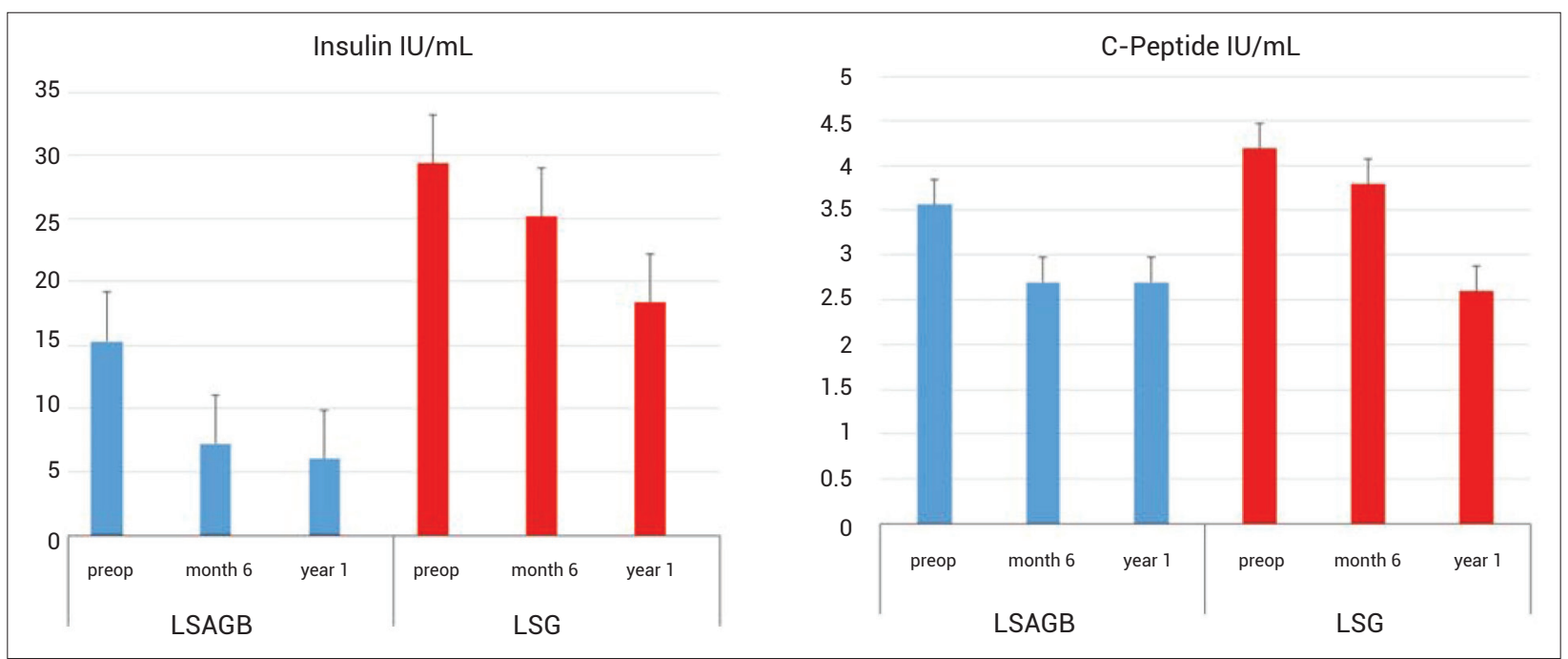

Figure 2. Insulin and C-peptide levels before and after LSG vs. LSAGB.

Furthermore, preoperative serum insulin and C-peptide which were $29.4(15.4-40.9) \mathrm{IU} / \mathrm{mL}$ and $4.2(2.3-5.3) \mathrm{IU} / \mathrm{mL}$ dropped to $18.4(9.7-20.3) \mathrm{IU} / \mathrm{mL}$ and $2.6(1.4-3.9) \mathrm{IU} / \mathrm{mL}$. Results are shown in Table 3 and Figures 1-3.

LSAGB is superior to LSG in terms of body weight control

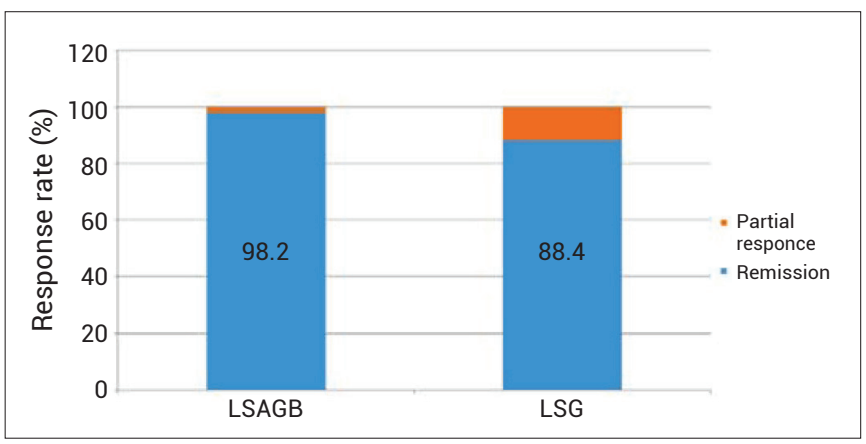

Figure 3. Response rates at the end of 18 months. and control of T2D. Metabolic effects of LSAGB start in early postoperative period; therefore, there must be factors other than weight loss involved in the efficacy.

\section{Conclusion}

Since the first attempt of obesity surgery by Victor Henriksson, new operations with large number of modifications have been described..$^{[55,56]}$ After over 60 years of research, bariatric surgery has proven to be the most effective mode of treatment for morbid obesity with increased safety and reduced mortality as well as a decreased risk of developing new health-related comorbidities.

It has also been proven to be the most effective means of metabolic surgery for T2D; however, there are many questions yet to be answered: What is the proper timing of sur- 
gery relative to other type 2 diabetes therapies? As long diabetes duration is the strongest predictor of postoperative non-remission surgery, could it be considered earlier in the disease rather than only as salvage therapy? How do various operations compare with one another? What is the full risk: benefit ratio of classical operations in less obese patients with type 2 diabetes, and how low a BMI might we contemplate? What about the long term effects? What are the exact mechanisms of metabolic effects?

We need to work hard, publish studies and wait for others to publish their results to see and learn more about the future of bariatric surgery.

\section{References}

1. Resnick HE, Foster GL, Bardsley J, Ratner RE. Achievement of American Diabetes Association clinical practice recommendations among U.S. adults with diabetes, 1999-2002: the National Health and Nutrition Examination Survey. Diabetes Care 2006;29:531-7.

2. WHO. Fact sheet no 311-312. Available at: http://www.who.int/ mediacentre/factsheets/fs311/en/. Accessed May 24, 2017.

3. Wong K, Glovaci D, Malik S, Franklin SS, Wygant G, Iloeje U, et al. Comparison of demographic factors and cardiovascular risk factor control among U.S. adults with type 2 diabetes by insulin treatment classification. J Diabetes Complications 2012;26:169-74.

4. Ferrannini E, Natali A, Bell P, Cavallo-Perin P, Lalic N, Mingrone $G$. Insulin resistance and hypersecretion in obesity. European Group for the Study of Insulin Resistance (EGIR). J Clin Invest 1997;100:1166-73.

5. Pal A, McCarthy MI. The genetics of type 2 diabetes and its clinical relevance. Clin Genet 2013;83:297-306.

6. Unwin N, Gan D, Whiting D. The IDF Diabetes Atlas: providing evidence, raising awareness and promoting action. Diabetes Res Clin Pract 2010;87:2-3.

7. Bays H, Mandarino L, DeFronzo RA. Role of the adipocyte, free fatty acids, and ectopic fat in pathogenesis of type 2 diabetes mellitus: peroxisomal proliferator-activated receptor agonists provide a rational therapeutic approach. J Clin Endocrinol Metab 2004;89:463-78.

8. Pories WJ. Why Does the Gastric Bypass Control Type 2 Diabetes Mellitus? Obes Surg 1992;2:303-13.

9. Rubino F, Schauer PR, Kaplan LM, Cummings DE. Metabolic surgery to treat type 2 diabetes: clinical outcomes and mechanisms of action. Annu Rev Med 2010;61:393-411.

10. Tham JC, Howes N, le Roux CW. The role of bariatric surgery in the treatment of diabetes. Ther Adv Chronic Dis 2014;5:149-57.

11. Pok EH, Lee WJ. Gastrointestinal metabolic surgery for the treatment of type 2 diabetes mellitus. World J Gastroenterol 2014;20:14315-28.

12. Schauer PR, Burguera B, Ikramuddin S, Cottam D, Gourash W,
Hamad G, et al. Effect of laparoscopic Roux-en Y gastric bypass on type 2 diabetes mellitus. Ann Surg 2003;238:467-84.

13. Buse JB, Caprio S, Cefalu WT, Ceriello A, Del Prato S, Inzucchi $\mathrm{SE}$, et al. How do we define cure of diabetes? Diabetes Care 2009;32:2133-5.

14. Brethauer SA, Aminian A, Romero-Talamás $H$, Batayyah $E$, Mackey J, Kennedy L, et al. Can diabetes be surgically cured? Long-term metabolic effects of bariatric surgery in obese patients with type 2 diabetes mellitus. Ann Surg 2013;258:62836.

15. Pories WJ, Swanson MS, MacDonald KG, Long SB, Morris PG, Brown BM, et al. Who would have thought it? An operation proves to be the most effective therapy for adult-onset diabetes mellitus. Ann Surg 1995;222:339-50.

16. Dixon JB, O'Brien PE, Playfair J, Chapman L, Schachter LM, Skinner $\mathrm{S}$, et al. Adjustable gastric banding and conventional therapy for type 2 diabetes: a randomized controlled trial. JAMA 2008;299:316-23.

17. Gill RS, Birch DW, Shi X, Sharma AM, Karmali S. Sleeve gastrectomy and type 2 diabetes mellitus: a systematic review. Surg Obes Relat Dis 2010;6:707-13.

18. DeMaria EJ, Sugerman HJ, Kellum JM, Meador JG, Wolfe LG. Results of 281 consecutive total laparoscopic Rouxen- $Y$ gastric bypasses to treat morbid obesity. Ann Surg 2002;235:640-5.

19. Cohen RV, Pinheiro JC, Schiavon CA, Salles JE, Wajchenberg $B L$, Cummings DE. Effects of gastric bypass surgery in patients with type 2 diabetes and only mild obesity. Diabetes Care 2012;35:1420-8.

20. Dixon JB, Zimmet P, Alberti KG, Mbanya JC, Rubino F; International Diabetes Federation Taskforce on Epidemiology and Prevention. Bariatric surgery for diabetes: the International Diabetes Federation takes a position. J Diabetes 2011;3:261-4.

21. American Diabetes Association. Standards of medical care in diabetes-2013. Diabetes Care 2013;36(Supplement 1): S11s66.

22. Rubino F, Gagner M. Potential of surgery for curing type 2 diabetes mellitus. Ann Surg 2002;236:554-9.

23. Rubino F. Bariatric surgery: effects on glucose homeostasis. Curr Opin Clin Nutr Metab Care 2006;9:497-507.

24. Buchwald H, Avidor Y, Braunwald E, Jensen MD, Pories W, Fahrbach K, et al. Bariatric surgery: a systematic review and meta-analysis. JAMA 2004;292:1724-37.

25. Allen RE, Hughes TD, Ng JL, Ortiz RD, Ghantous MA, Bouhali $O$, et al. Mechanisms behind the immediate effects of Rouxen-Y gastric bypass surgery on type 2 diabetes. Theor Biol Med Model 2013;10:45.

26. Lee WJ, Chong K, Chen CY, Chen SC, Lee YC, Ser KH, et al. Diabetes remission and insulin secretion after gastric bypass in patients with body mass index $<35 \mathrm{~kg} / \mathrm{m} 2$. Obes Surg 2011;21:889-95.

27. Lee WJ, Lee YC, Ser KH, Chen JC, Chen SC. Improvement of insulin resistance after obesity surgery: a comparison of gastric banding and bypass procedures. Obes Surg 
2008;18:1119-25.

28. Pournaras DJ, Osborne A, Hawkins SC, Vincent RP, Mahon $D$, Ewings $P$, et al. Remission of type 2 diabetes after gastric bypass and banding: mechanisms and 2 year outcomes. Ann Surg 2010;252:966-71.

29. Laferrère $B$, Teixeira J, McGinty J, Tran H, Egger JR, Colarusso $A$, et al. Effect of weight loss by gastric bypass surgery versus hypocaloric diet on glucose and incretin levels in patients with type 2 diabetes. J Clin Endocrinol Metab 2008;93:2479-85.

30. Cummings DE, Shannon MH. Roles for ghrelin in the regulation of appetite and body weight. Arch Surg 2003;138:389-96.

31. Tymitz K, Engel A, McDonough S, Hendy MP, Kerlakian G. Changes in ghrelin levels following bariatric surgery: review of the literature. Obes Surg 2011;21:125-30.

32. Patrikakos P, Toutouzas KG, Gazouli M, Perrea D, Menenakos E, Papadopoulos S, et al. Long-term plasma ghrelin and leptin modulation after sleeve gastrectomy in Wistar rats in comparison with gastric tissue ghrelin expression. Obes Surg 2011;21:1432-7.

33. Tong J, Prigeon RL, Davis HW, Bidlingmaier M, Kahn SE, Cummings DE, et al. Ghrelin suppresses glucose-stimulated insulin secretion and deteriorates glucose tolerance in healthy humans. Diabetes 2010;59:2145-51.

34. Rubino F, Forgione A, Cummings DE, Vix M, Gnuli D, Mingrone $G$, et al. The mechanism of diabetes control after gastrointestinal bypass surgery reveals a role of the proximal small intestine in the pathophysiology of type 2 diabetes. Ann Surg 2006;244:741-9.

35. Cummings DE, Overduin J, Foster-Schubert KE, Carlson MJ. Role of the bypassed proximal intestine in the anti-diabetic effects of bariatric surgery. Surg Obes Relat Dis 2007;3:109-15.

36. Aguirre V, Stylopoulos N, Grinbaum R, Kaplan LM. An endoluminal sleeve induces substantial weight loss and normalizes glucose homeostasis in rats with diet-induced obesity. Obesity (Silver Spring) 2008;16:2585-92.

37. Rodriguez-Grunert L, Galvao Neto MP, Alamo M, Ramos AC, Baez PB, Tarnoff M. First human experience with endoscopically delivered and retrieved duodenal-jejunal bypass sleeve. Surg Obes Relat Dis 2008;4:55-9.

38. Geloneze B, Geloneze SR, Chaim E, Hirsch FF, Felici AC, Lambert $\mathrm{G}$, et al. Metabolic surgery for non-obese type 2 diabetes: incretins, adipocytokines, and insulin secretion/resistance changes in a 1-year interventional clinical controlled study. Ann Surg 2012;256:72-8.

39. Rhee NA, Vilsbøll T, Knop FK. Current evidence for a role of GLP-1 in Roux-en-Y gastric bypass-induced remission of type 2 diabetes. Diabetes Obes Metab 2012;14:291-8.

40. Butler PC, Dry S, Elashoff R. GLP-1-based therapy for diabetes: what you do not know can hurt you. Diabetes Care 2010;33:453-5.

41. Borg CM, le Roux CW, Ghatei MA, Bloom SR, Patel AG, Aylwin SJ. Progressive rise in gut hormone levels after Roux-en-Y gastric bypass suggests gut adaptation and explains altered satiety. Br J Surg 2006;93:210-5.

42. Kootte RS, Vrieze A, Holleman F, Dallinga-Thie GM, Zoetendal
EG, de Vos WM, et al. The therapeutic potential of manipulating gut microbiota in obesity and type 2 diabetes mellitus. Diabetes Obes Metab 2012;14:112-20.

43. Felig P, Marliss E, Cahill GF Jr. Plasma amino acid levels and insulin secretion in obesity. N Engl J Med 1969;281:811-6.

44. Pournaras DJ, Glicksman C, Vincent RP, Kuganolipava S, Alaghband-Zadeh J, Mahon D, et al. The role of bile after Roux-en-Y gastric bypass in promoting weight loss and improving glycaemic control. Endocrinology 2012;153:3613-9.

45. Werling $M$, Olbers T, Fändriks L, Bueter $M$, Lönroth $H$, Stenlöf $\mathrm{K}$, et al. Increased postprandial energy expenditure may explain superior long term weight loss after Roux-en-Y gastric bypass compared to vertical banded gastroplasty. PLoS One 2013;8:e60280.

46. Carlsson LM, Peltonen M, Ahlin S, Anveden $\AA$, Bouchard $C$, Carlsson B, et al. Bariatric surgery and prevention of type 2 diabetes in Swedish obese subjects. N Engl J Med 2012;367:695-704.

47. Sjöström L, Peltonen M, Jacobson P, Ahlin S, Andersson-Assarsson J, Anveden $\AA$, et al. Association of bariatric surgery with long-term remission of type 2 diabetes and with microvascular and macrovascular complications. JAMA 2014;311:2297-304.

48. Chang SH, Stoll CR, Song J, Varela JE, Eagon CJ, Colditz GA. The effectiveness and risks of bariatric surgery: an updated systematic review and meta-analysis, 2003-2012. JAMA Surg 2014;149:275-87.

49. Schauer PR, Kashyap SR, Wolski K, Brethauer SA, Kirwan JP, Pothier $\mathrm{CE}$, et al. Bariatric surgery versus intensive medical therapy in obese patients with diabetes. N Engl J Med 2012;366:1567-76.

50. Schauer PR, Bhatt DL, Kirwan JP, Wolski K, Brethauer SA, Navaneethan SD, et al; STAMPEDE Investigators. Bariatric surgery versus intensive medical therapy for diabetes--3-year outcomes. N Engl J Med 2014;370:2002-13.

51. Ribaric G, Buchwald JN, McGlennon TW. Diabetes and weight in comparative studies of bariatric surgery vs conventional medical therapy: a systematic review and meta-analysis. Obes Surg 2014;24:437-55.

52. Lee WJ, Chong K, Lin YH, Wei JH, Chen SC. Laparoscopic sleeve gastrectomy versus single anastomosis (mini-) gastric bypass for the treatment of type 2 diabetes mellitus: 5 -year results of a randomized trial and study of incretin effect. Obes Surg 2014;24:1552-62.

53. Lee WJ, Hur KY, Lakadawala M, Kasama K, Wong SK, Lee YC. Gastrointestinal metabolic surgery for the treatment of diabetic patients: a multi-institutional international study. J Gastrointest Surg 2012;16:45-51.

54. Ozmen MM, Sahin TT, Gundogdu E, Moran M, Isgenderova S. Mini gastric bypass on type 2 diabetes mellitus: fast, safe and effective. Obesity Surgery 2014;24:1257.

55. Enrikson V. Kan tuntarnresektion forsuarassom terapi mot fettsot. Nordisk Med 1952;47:744-7.

56. Scopinaro N. Bariatric metabolic surgery. Rozhl Chir 2014;93:404-15. 